\title{
Method validation to assess in vivo cellular and subcellular changes in buccal mucosa cells and saliva following CBCT examinations
}

\author{
${ }^{1,2}$ Niels Belmans, ${ }^{1}$ Liese Gilles, ${ }^{3}$ Piroska Virag, ${ }^{3}$ Mihaela Hedesiu, ${ }^{4}$ Benjamin Salmon, ${ }^{2}$ Sarah Baatout, \\ ${ }^{5}$ Stéphane Lucas, ${ }^{6,7}$ Reinhilde Jacobs, ${ }^{1}$ Ivo Lambrichts and ${ }^{2}$ Marjan Moreels \\ ${ }^{1}$ Morphology Group, Biomedical Research Institute, Hasselt University, Diepenbeek, Belgium; ${ }^{2}$ Belgian Nuclear Research Centre, \\ Radiobiology Unit, SCK•CEN, Mol, Belgium; '“'Iuliu Hatieganu' University of Medicine and Pharmacy, Department of Oral and \\ Maxillofacial Radiology, Cluj-Napoca, Romania; ${ }^{4}$ Department of Orofacial Pathologies, Imaging and Biotherapies Lab and Dental \\ Medicine, Paris Descartes University - Sorbonne Paris Cité, Bretonneau Hospital, HUPNVS, AP-HP, Paris, France; ${ }^{5}$ University \\ of Namur, Research Institute for Life Sciences, Namur, Belgium; ${ }^{6}$ Department of Imaging and Pathology Katholieke Universiteit \\ Leuven, OMFS IMPATH Research Group, and University Hospitals, Oral and Maxillofacial Surgery, Dentomaxillofacial Imaging \\ Center, Leuven, Belgium; ${ }^{7}$ Department Dental Medicine, Karolinska Institutet, Huddinge, Sweden
}

Objectives: Cone-beam CT (CBCT) is a medical imaging technique used in dental medicine. However, there are no conclusive data available indicating that exposure to X-ray doses used by CBCT are harmless. We aim, for the first time, to characterize the potential age-dependent cellular and subcellular effects related to exposure to CBCT imaging. Current objective is to describe and validate the protocol for characterization of cellular and subcellular changes after diagnostic CBCT.

Methods: Development and validation of a dedicated two-part protocol: 1) assessing DNA double strand breaks (DSBs) in buccal mucosal (BM) cells and 2) oxidative stress measurements in saliva samples. BM cells and saliva samples are collected prior to and $0.5 \mathrm{~h}$ after $\mathrm{CBCT}$ examination. BM cells are also collected $24 \mathrm{~h}$ after CBCT examination. DNA DSBs are monitored in BM cells via immunocytochemical staining for $\gamma \mathrm{H} 2 \mathrm{AX}$ and 53BP1. 8-oxo-7,8-dihydro-2'-deoxyguanosine (8-oxo-dG) and total antioxidant capacity are measured in saliva to assess oxidative damage.

Results: Validation experiments show that sufficient BM cells are collected $(97.1 \pm 1.4 \%)$ and that $\gamma \mathrm{H} 2 \mathrm{AX} / 53 \mathrm{BP} 1$ foci can be detected before and after CBCT examination. Collection and analysis of saliva samples, either sham exposed or exposed to IR, show that changes in 8-oxo-dG and total antioxidant capacity can be detected in saliva samples after CBCT examination.

Conclusion: The DIMITRA Research Group presents a two-part protocol to analyze potential age-related biological differences following CBCT examinations. This protocol was validated for collecting BM cells and saliva and for analyzing these samples for DNA DSBs and oxidative stress markers, respectively.

Dentomaxillofacial Radiology (2019) 48, 20180428. doi: 10.1259/dmfr.20180428

Cite this article as: Belmans N, Gilles L, Virag P, Hedesiu M, Salmon B, Baatout S, et al. Method validation to assess in vivo cellular and subcellular changes in buccal mucosa cells and saliva following CBCT examinations. Dentomaxillofac Radiol 2019; 48: 20180428.

Keywords: Dental cone-beam CT; DNA Double strand breaks; Oxidative stress; Buccal mucosal cells; Saliva 


\section{Introduction}

Dental cone-beam CT (CBCT) is a relatively new and innovative diagnostic imaging technique introduced in oral health care at the turn of the century. ${ }^{1,2}$ Its growing use lies in the diagnostic potential related to the transition from two-dimensional (2D) to three-dimensional (3D) dentomaxillofacial diagnostic imaging. ${ }^{3-6} \mathrm{CBCT}$ uses a cone-shaped X-ray beam and a 2D detector to generate 3D images. Briefly, the source-detector rotates around the patient once, while generating a series of $2 \mathrm{D}$ images. These images are then reconstructed into a 3D volume data set using a specialized algorithm., ${ }^{3,-9}$ Specifically designed to produce cross-sectional images of the oral and maxillofacial region, combined with its low cost and easy accessibility, CBCT technology has rapidly evolved in the past decade. Nowadays it has become a widely available diagnostic tool for clinicians and has therefore found applications in multiple dental specialties, including implant planning, endodontics, orthodontics and maxillofacial surgery. ${ }^{1,2,4,8,10-12}$

Like other medical imaging techniques, such as CT, CBCT uses X-rays for its image acquisition. However, ionizing radiation (IR) is capable of damaging biomolecules (e.g., DNA or proteins) directly or indirectly via the hydrolysis of water which generates free radicals, such as reactive oxygen species (ROS). ${ }^{13,14}$ Although $\mathrm{CBCT}$ is defined as a low dose imaging technique by the European High-Level Expert Group on European Low Dose Risk Research (HLEG) (www.hleg.de), it is misleading to see it as a 'low-dose' imaging modality just because it only takes one rotation compared to multiple rotations in conventional CT. As in CT, the absorbed dose in CBCT heavily depends on selectable exposure parameters that determine the image quality such as $\mathrm{kVp}, \mathrm{mAs}$, field of view (FOV), amount of 2D projections, reconstitution algorithm, etc.. ${ }^{415-18}$ Therefore, a wide range of CBCT doses is observed, typically ranging from about 0.010 to $1.100 \mathrm{mSv}$ per examination. ${ }^{15,17-22} \mathrm{CBCT}$ doses are lower than CT doses (organ dose of about $15 \mathrm{mSv}$ ), however, they are higher than classical 2D dental radiography techniques (organ dose of $0.001-0.1 \mathrm{mSv}){ }^{4,16,23-26}$

More recently, the dose of ionizing radiation delivered to pediatric patients has become a major concern among clinicians worldwide. ${ }^{20,24}$ In 2010, the New York Times was the first major newspaper to bring this concern to the attention of the general public when they published the article entitled "Radiation Worries for Children in Dentists' Chairs". ${ }^{27}$ In practice, especially in orthodontics, a large portion of CBCT examinations is performed on children ( $<18$ years old), who are known to be more radiosensitive than adults. ${ }^{18,28-30}$ These concerns about the dose, combined with an increasing amount of radiological examinations annually, have led to questions about the biological uncertainties associated with radiation-induced health risks at low doses in dental radiology. ${ }^{24,31,32}$
Exposure to IR, such as X-rays, could result in damage to important biomolecules, either directly, but mostly indirectly via generation of free radicals, usually through hydrolysis of water. These radicals (e.g., reactive oxygen species (ROS)) can in turn damage biomolecules in nano- to microseconds. ${ }^{14}$ Since more than $60 \%$ of a cell consists of water, most of the DNA damage is caused indirectly via ROS (e.g., the hydroxyl radical, superoxide radicals and hydrogen peroxide). ${ }^{25,33}$ An excess of ROS causes oxidative stress. In the context of oral pathology, oxidative stress is associated with periodontitis, dental caries and oral cancers. ${ }^{34,35}$ ROS can cause oxidative DNA damage through oxidative base lesions, of which over 20 different lesions have been identified. ${ }^{36}$ An example hereof is 8-oxo-7,8-dihydro-2'-deoxyguanosine (8-oxo-dG), a mutagenic base modification. ${ }^{37}$ Other types of DNA lesions include single strand breaks, double strand breaks (DSBs) and base alterations. ${ }^{33,38}$ DNA double strand breaks (DSBs) are the most critical DNA lesions caused by IR. When not repaired correctly, DSBs can lead to chromosome rearrangements, mutations and loss of genetic information. ${ }^{39-44}$ To protect themselves, eukaryotic cells have developed the DNA damage response (DDR), a set of signaling and DNA repair pathways. ${ }^{45-47}$

Human buccal mucosa (BM) cells are useful for determining exposure to several environmental factors. ${ }^{48,49}$ Furthermore, BM cells are an easy accessible source of cells that can be sampled in a minimally invasive way. ${ }^{50,51}$ As such, they are being increasingly used to investigate the effects of exposure to genotoxins that can cause DNA damage and cell death. ${ }^{48,51,52}$

Another easy accessible biological sample is saliva, which, like BM cells, is easy to collect in an inexpensive, painless and non-invasive way. ${ }^{53}$ Known as the "mirror of the body', saliva is finding its way to research and the clinic as a diagnostic fluid..$^{35,54,55}$ To date, the salivary metabolome has been described and saliva has been used to link oxidative stress markers to several oral diseases, such as dental caries and periodontitis. ${ }^{34,35,56}$

Effective dose (ED), measured in $\mathrm{mSv}$, is a dose quantity that takes following factors into account: 1) the absorbed dose to all organs of the body, 2) the relative harm of the type of radiation, and 3) the radiosensitivity of each organ. Although ED is an accepted term since its introduction in radiation protection, it is often criticized. For example the weighing factors used to calculate the ED are determined by scientific committees and may evolve over time. ${ }^{57-59}$ Furthermore, the ED is independent of gender and age at exposure, whereas epidemiological data indicate that both gender and age at exposure are important parameters. ${ }^{60}$

A European project funded by the Open Project for European Radiation Research Area (OPERRA) denoted as DIMITRA (Dentomaxillofacial Paediatric Imaging: An Investigation Towards Low Dose 
Radiation Induced Risks) was initiated in order to characterize any potential cellular and subcellular effects induced by dental CBCT imaging, with a focus on ageand gender specificity and with reference to simulated ED (www.dimitra.be). In vitro results from DIMITRA were published previously, showing transient increases in DNA DSBs and changes in inflammatory cytokines after CBCT exposure of dental stem cells in vitro. ${ }^{61}$ The objective of the present report is to describe and validate a two-part protocol enabling the DIMITRA project to assess the potential age-related cellular and subcellular effects using DNA DSB detection in buccal mucosal cells and salivary oxidative stress measurement. To the best of our knowledge, a protocol and method validation for characterizing cellular and subcellular effects of CBCT exposure has not yet been described.

\section{methods and materials}

\section{Description of the DIMITRA protocol}

Synthetic swabs (EpiCentre ${ }^{\circledR}$, Madison, WI) are used to collect BM cells from eligible patients. Eligibility criteria are: having no systemic or acute diseases, taking no medication (antibiotics or anti inflammatory drugs), having a good oral hygiene and giving informed consent prior to conclusion. When eligible, patients were asked to complete a questionnaire (Supplementary Material 1) . At least one hour prior to BM cell collection, subjects are asked not to eat, brush their teeth or smoke. Just before BM cell collection, subjects rinse their mouth twice with water to remove excess debris. BM cells are collected from each patient just before, $0.5 \mathrm{~h}$ after and $24 \mathrm{~h}$ after CBCT examination (Figure 1), using a protocol modified from Thomas et al. (2009). ${ }^{50}$ The $24 \mathrm{~h}$ samples are collected at the patients' homes. To this end patients receive detailed instruction sheets (Supplementary Material 2). After collection, samples are sent to $\mathrm{SCK} \cdot \mathrm{CEN}$ via a professional courier service.

\section{Buccal mucosal cell collection and fixation}

Per patient six $15 \mathrm{ml}$ conical tubes $\left(\right.$ Cellstar $^{\circledR}$, Greiner Bio-One, Vilvoorde, Belgium) (one for each time point and cheek side) containing $10 \mathrm{ml}$ of Saccomanno's fixative (SF) $(50 \%$ ethanol, $2 \%$ polyethylene glycol, $48 \%$ MilliQ water) are prepared. The swab is taken out of the package by the plastic handle. It is important not to touch the swab itself. Then the swab is placed against the middle of the patient's cheek. For reproducibility, the same cheek was used every time. Next, it is pressed firmly against the cheek and moved in an upward-downward motion while turning the swab for at least $30 \mathrm{sec}$. The swab is then placed into SF in the $15 \mathrm{ml}$ conical tube and shaken in such a manner that the cells are dislodged and released into SF. The tubes are then stored at $4^{\circ} \mathrm{C}$ (for up to 7 days) before shipment to SCK $\cdot \mathrm{CEN}$ by courier service.

Within 7 days after sample collection, the BM cells are harvested from SF. For this purpose, the $15 \mathrm{ml}$ conical tubes are centrifuged at $580 \mathrm{~g}$ for $10 \mathrm{~min}$ at room temperature (RT). The supernatant is aspirated

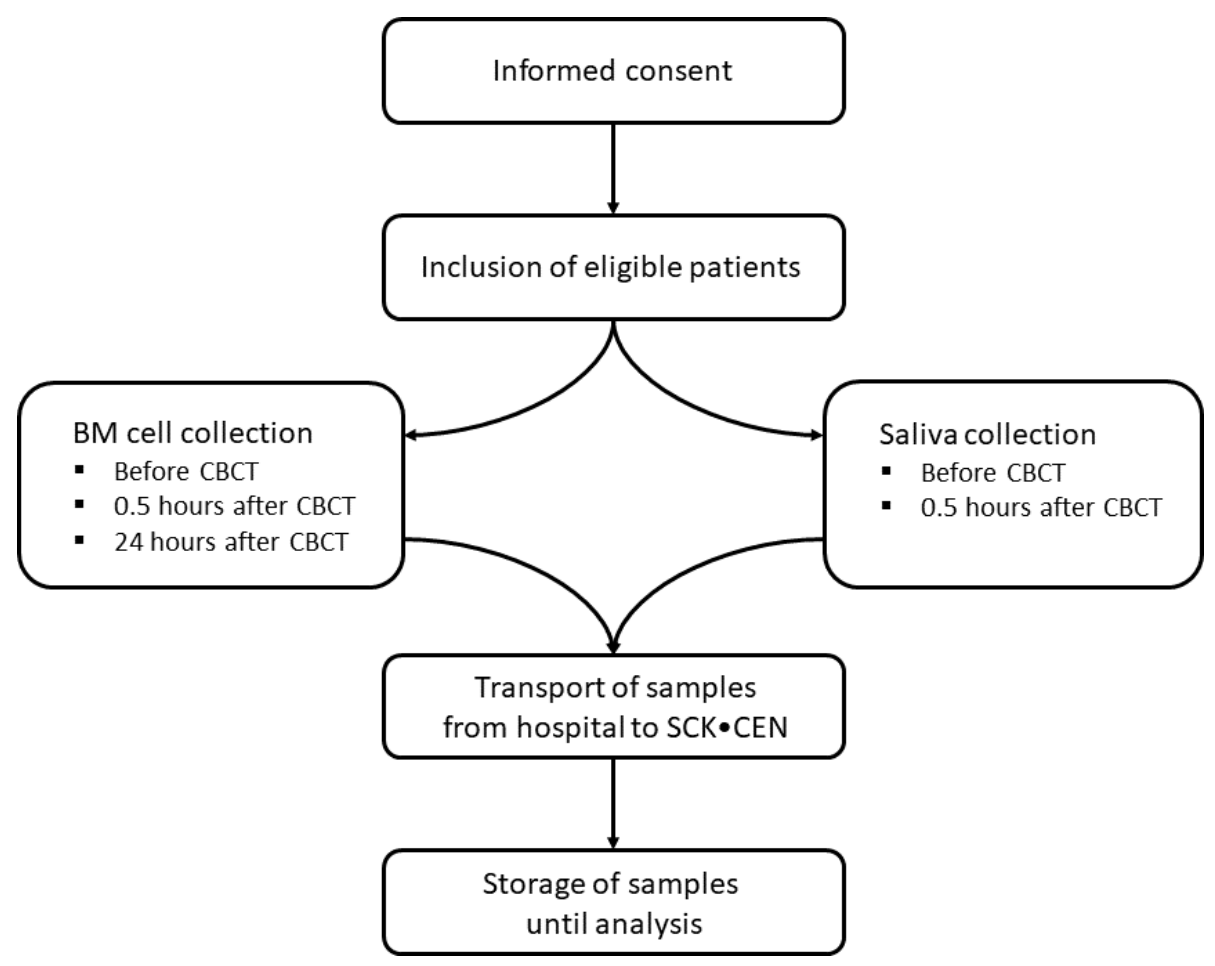

Figure 1 Flow chart for patient inclusion and patient sampling. CBCT. cone beam CT; BM, Buccal mucosa. 
until about $1 \mathrm{ml}$ is left. $5 \mathrm{ml}$ of autoclaved buccal buffer $(\mathrm{BuBu})(0.01 \mathrm{M}$ Tris-HCl, 0.1 M EDTA, $0.02 \mathrm{M} \mathrm{NaCl}$, $1 \% \mathrm{FBS}, \mathrm{pH}=7)$ is added to the tube, after which the cells are vortexed briefly. Then, the cells are centrifuged at $580 \mathrm{~g}$ for $10 \mathrm{~min}$ at RT. The supernatant is removed completely and the cells are washed with $5 \mathrm{ml} \mathrm{BuBu}$ and centrifuged at $580 \mathrm{~g}$ for $10 \mathrm{~min}$ at RT. This washing step is repeated twice to inactivate DNAses from the oral cavity and to remove excess debris and bacteria. After washing, the supernatant is removed and the cells are resuspended in $5 \mathrm{ml}$ of $\mathrm{BuBu}$ and vortexed briefly. Next, the BM cells are passed through a $100 \mu \mathrm{m}$ nylon filter (Falcon ${ }^{\circledR}$, VWR Belgium, Leuven, Belgium) into a 50 $\mathrm{ml}$ conical tube $\left(\right.$ Cellstar $^{\circledR}$, Greiner Bio-One, Vilvoorde, Belgium) to remove large aggregates of unseparated cells. The $50 \mathrm{ml}$ conical tube holding the filter is then centrifuged at $580 \mathrm{~g}$ for $10 \mathrm{~min}$ at RT. Afterwards, the BM cells in the filtrate are transferred to a new $15 \mathrm{ml}$ conical tube. Then the BM cells are centrifuged one last time at $580 \mathrm{~g}$ for $5 \mathrm{~min}$ at RT. The supernatant is removed and the BM cells are resuspended in $1 \mathrm{ml}$ of $\mathrm{BuBu}$. The BM cells are then centrifuged at $580 \mathrm{~g}$ for $5 \mathrm{~min}$ at RT and the supernatant is discarded afterwards. Then, the BM cells are fixed in $500 \mu \mathrm{l}$ of $2 \%$ paraformaldehyde (PFA) (Sigma Aldrich, St-Louis, MO) while vortexing the BM cells and adding the PFA dropwise. The BM cells are incubated for at least $15 \mathrm{~min}$ at RT. After incubation, the $\mathrm{BM}$ cells are centrifuged at $580 \mathrm{~g}$ for $5 \mathrm{~min}$. The supernatant is discarded and the BM cells are washed twice using $1 \times$ phosphate-buffered saline (PBS) (Gibco, Life Technologies, Ghent, Belgium). After the last washing step, the BM cells are resuspended in $1 \mathrm{ml} 1 \times \mathrm{PBS}$. The $\mathrm{BM}$ cells can now be stored at $4^{\circ} \mathrm{C}$ for a longer period or used immediately for immunocytochemical staining.

\section{Immunocytological staining for DNA double strand breaks: $\gamma H 2 A X$ and $53 b p 1$ staining}

Before immunocytochemical staining, the BM cells need to be transferred from the $15 \mathrm{ml}$ conical tubes to coverslips by cytocentrifugation. The BM cells are washed using $200 \mu \mathrm{l}$ of $1 \mathrm{x}$ PBS twice. During washing, poly-Llysine coated coverslips, which assure good attachment of the BM cells, are placed on a microscope slide which is then inserted in a cytofunnel (ThermoFisher, Waltham, MA). Next, $100 \mu \mathrm{l}$ of cell suspension is pipetted into each sample cup of a Cytofunnel. The cytofunnels are centrifuged at $1200 \mathrm{rpm}$ for $10 \mathrm{~min}$ in a cytocentrifuge (ThermoFisher, Waltham, MA) at RT, causing the BM cells to adhere to the coverslip inside the cytofunnel. After centrifugation, the coverslips are removed and placed into a 4-well culture plate (Nunc, ThermoFisher Scientific, Roskilde, Denmark) so the BM cells are facing up. The BM cells are allowed to air-dry for 2 min at RT.

Immunocytochemical staining was performed using a protocol as previously described by our group. ${ }^{62-64}$ First the BM cells are washed twice using cold 1x PBS for 5 min on a rocking platform. After washing, the BM cells are permeabilized for 3 min using $0.25 \%$ Triton
X-100 in 1x PBS at RT. Next, the BM cells are washed three times with $1 \times \mathrm{PBS}$. Then the $\mathrm{BM}$ cells are blocked with 1x pre-immunized goat serum (ThermoFisher Scientific, Waltham, MA) in a solution of $1 \times$ TBST, $0.005 \mathrm{~g} / \mathrm{v} \%$ TSA blocking powder (PerkinElmer, FP1012, Zaventem, Belgium) (TNB) for $1 \mathrm{~h}$ at RT. After blocking the primary mouse monoclonal anti- $\gamma \mathrm{H} 2 \mathrm{AX}$ antibody (Millipore 05-636, Merck, Overijse, Belgium) (1:300 in TNB) and rabbit polyclonal anti-53BP1 antibody (Novus Biologicals NB100-304, Abingdon, UK) (1:1000 in TNB) are added. Next, the BM cells are incubated overnight at $4^{\circ} \mathrm{C}$ on a rocking platform. After incubation, the BM cells are washed three times with $1 \times$ PBS. Then the secondary goat anti mouse Alexa Fluor $^{\circledR}$ 488-labeled antibody (1:300 in TNB) and goat anti rabbit Alexa Fluor ${ }^{\circledR}$ 568-labeld antibody (1:1000 in TNB) (ThermoFisher Scientific, A11001, Waltham, MA) were added. The BM cells are incubated for $1 \mathrm{~h}$ on a rocking platform in the dark. Afterwards, the BM cells are washed twice using $1 \times$ PBS. Next, slides are mounted with ProLong Diamond antifade medium with 4',6-diamidino-2-phenylindole (DAPI) (ThermoFisher Scientific, Waltham, MA).

Finally, images are acquired with a Nikon Eclipse Ti fluorescence microscope using a $40 \times$ dry objective (Nikon, Tokyo, Japan). Images are analyzed using open source Fiji software. ${ }^{65}$ The software allows to analyze each nucleus based on the DAPI signal. Within each nucleus, the intensity signals from the Alexa 488 and Alexa 568 fluorochromes are analyzed after which the number of co-localized $\gamma \mathrm{H} 2 \mathrm{AX}$ and 53BP1 foci per nucleus are determined in an automated manner using the Cellblocks toolbox (Figure 2). ${ }^{6}$

\section{Saliva collection and analysis}

Saliva samples are collected right before and $0.5 \mathrm{~h}$ after CBCT examination (Figure 1) using the passive drool method, which is considered to be the 'gold standard' for saliva sampling. ${ }^{67}$ As with the BM cells (saliva is sampled at the same time), subjects are asked not to eat, brush their teeth or smoke one hour prior to saliva sampling. Just before saliva collection, subjects will rinse their mouth twice with water to remove excess debris. If blood is detected in the saliva, the sample is not included for this study. The saliva samples will be stored at $-20^{\circ} \mathrm{C}$ immediately after collection before shipment to $\mathrm{SCK} \cdot \mathrm{CEN}$ by courier service. Once at $\mathrm{SCK} \cdot \mathrm{CEN}$ samples will be centrifuged at $10000 \mathrm{~g}$ at $4^{\circ} \mathrm{C}$ to remove most of the mucus and the supernatant will be stored at $-80^{\circ} \mathrm{C}$. The stored samples will be used to determine 8-oxo-dG concentrations and the total antioxidant capacity (Figure 2).

\section{8-oxo-dG determination}

8-oxo-dG concentrations will be determined by competitive enzyme-linked immunosorbent assay (ELISA) (Health Biomarkers Sweden AB, Stockholm, Sweden). To remove substances other than 8-oxo-dG which 


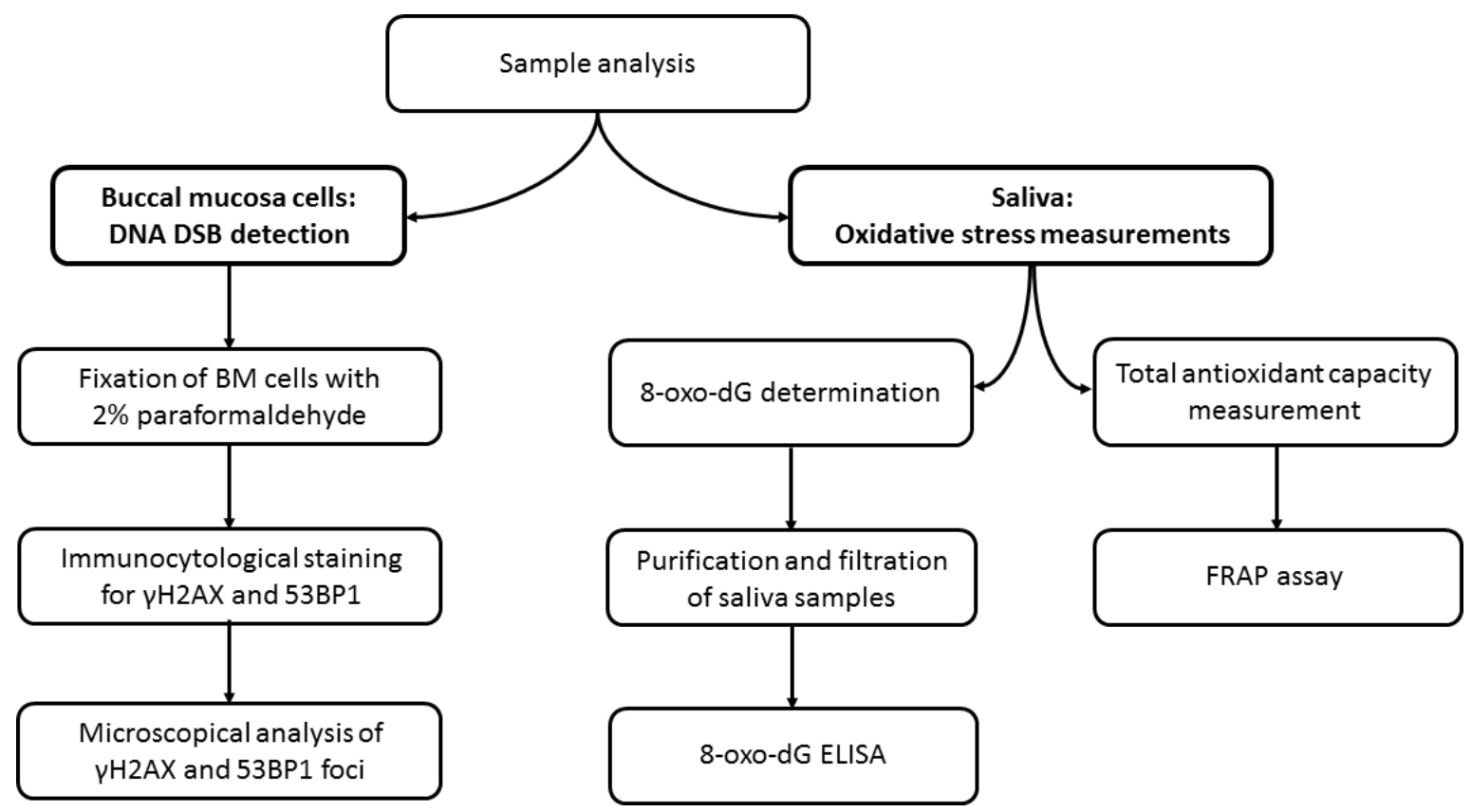

Figure 2 Flow chart for sample analysis. Schematic view of DNA double strand break detection in buccal mucosal cells and oxidative stress measurements in saliva samples. DSB, double-strand break; BM, Buccal mucosa; $\gamma \mathrm{H} 2 \mathrm{AX}$, phosphorylated histone 2AX on Ser139; 53BP1, p53-binding protein 1; 8-oxo-dG, 8-oxo-7,8-dihydro-2'-deoxyguanosine; FRAP, ferric reducing antioxidant power; ELISA, enzyme-linked immunosorbent assay.

could cross-react with the monoclonal antibody used in the ELISA-kit, $800 \mu \mathrm{L}$ sample will be purified prior to ELISA using a C18 solid phase extraction column (Varian, Lake Forest, CA) after which the samples are freeze-dried. This purification is performed twice. ${ }^{68}$

The 8-oxo-dG concentration of saliva will be measured based on a modified ELISA protocol provided by Health Biomarkers Sweden AB (Stockholm, Sweden). The protocol will be performed as previously described by Haghdoost et al.. ${ }^{69}$ Briefly, $270 \mu$ of purified sample/ standard will be mixed with $165 \mu \mathrm{l}$ of primary antibody $\left(80 \mathrm{ng} \mathrm{ml}^{-1}\right.$ ) mix in Eppendorf tubes. Next the samples will be incubated for $2 \mathrm{~h}$ at $37^{\circ} \mathrm{C}$. During incubation, the ELISA plate will be washed twice using 1x PBS. After incubation $140 \mu \mathrm{l}$ of sample/standard will be loaded onto the plate in triplicate. The plate will be incubated overnight at $4^{\circ} \mathrm{C}$ on a horizontal shaker. Next the plate will be washed three times using $1 \mathrm{x}$ washing solution. After washing $140 \mu \mathrm{l}$ of secondary antibody mix is added to each well. The plate is incubated for $2 \mathrm{~h}$ at RT on a horizontal shaker. Next the plate is washed three times with $1 \mathrm{x}$ washing solution and once more with $1 \mathrm{x}$ PBS. Finally, the reaction is visualized by the addition of $140 \mu \mathrm{l}$ chromogenic substrate 3,3',5,5'-Tetramethylbenzidine (One-Step substrate system; Dako, Glostrup Municipality, Denmark), and further incubation in the dark for $15 \mathrm{~min}$. The reaction is stopped by adding 70 $\mu \mathrm{l}$ of $2 \mathrm{M} \mathrm{H}_{2} \mathrm{SO}_{4}$. The absorbance is measured at 450 $\mathrm{nm}$ (signal) and $570 \mathrm{~nm}$ (background) using a microplate reader (ClarioStar, BMG Labtech, Ortenberg, Germany) (Figure 2).

\section{Total antioxidant capacity}

To determine the antioxidant capacity of saliva samples, the ferric reducing antioxidant power (FRAP) assay is used (Cell Biolabs, CA). The FRAP assay will be performed according to the manufacturer's instructions. Briefly, per well of a 96-well plate $100 \mu \mathrm{l}$ of sample/ standard and $100 \mu \mathrm{l}$ of reaction reagent are added. Next the samples/standards are incubated for $10 \mathrm{~min}$ at RT on a horizontal shaker. Finally, the absorbance will be measured at $560 \mathrm{~nm}$ using a microplate reader (ClarioStar, BMG Labtech, Ortenberg, Germany). The results will be expressed as Iron(II) concentration $(\mu \mathrm{M})$ or FRAP value (Figure 2).

\section{Protocol validation}

Pilot study population: Healthy adults $(N=6)$ are included in this pilot study to validate the DIMITRA study protocol. These patients are referred for a CBCT examination. All patients were asked to sign informed consent forms prior to being included in the study. The validation study was approved by the ethical committees of the participating hospitals, since this is part of the scope of the DIMITRA study.

Flow cytometrical identification of buccal mucosal cells: Cells collected using the method described earlier are identified with the epithelial cell marker cytokeratin 4 (CK4) and lymphoid cell marker CD45 to identify the amount of BM cells collected with the swab. A431 and PC3 (courtesy of Katrien Konings, 
$\mathrm{SCK} \cdot \mathrm{CEN}$ ) cell lines are used as a positive control for CK4 expression. Jurkat cells are used as a positive control for CD45 expression.

All cells are washed with 1xPBS and fixed in ice-cold $\left(-20^{\circ} \mathrm{C}\right) 70 \%$ ethanol at a concentration of $1 \times 10^{6}$ cells $\mathrm{ml}^{-1}$ or $2 \times 10^{6}$ cells $\mathrm{ml}^{-1}$ (Jurkat). Next, cells are washed once with a solution of $1 \mathrm{x}$ PBS, 5\% FBS (GIBCO, Life Technologies, Ghent, Belgium) and $0.25 \%$ Triton X-100 (Sigma-Aldrich chemistry, St-Louis, MO) (PFT) and are then blocked for $1 \mathrm{~h}$ at RT in PFT. After blocking, cells are incubated with a rabbit anti-CK4 antibody (diluted 1:100 in PFT) overnight at $4^{\circ} \mathrm{C}$ on a horizontal shaker. Next, cells are washed twice with PFT. Subsequently, Alexa 488-conjugated donkey anti rabbit secondary antibody (diluted 1:200 in PFT) and primary mouse anti human CD45 antibody labelled with allophycocyanin (diluted 1:50 in PFT) are added and the cells were incubated for $2 \mathrm{~h}$ at RT in the dark. After incubation, the cells are washed twice with PFT and treated with $10 \mu \mathrm{g}$ $\mathrm{ml}^{-1}$ of the DNA dye 7-AminoActinomycin D (7-AAD) for $15 \mathrm{~min}$ at RT. 7-AAD is used to distinguish cellular material from debris. Furthermore, it gives information about the current cell cycle phase of the samples. Finally, the samples are filtered on a BD conical tube (Falcon ${ }^{\circledR}$, Corning, NY) and analyzed on the BD AccuriTM C6 Flow Cytometer (BD Biosciences, San Jose, CA). At least 10.000 events are measured. Single-colour stained cells are included for colour compensation. Gating is based on using A431, PC3 and Jurkat cells as positive/ negative control for CK4 or CD45. Cells in $\mathrm{G}_{1} / \mathrm{G}_{0}$ phase and $\mathrm{CK}^{+}$are identified as $\mathrm{BM}$ cells.

Histological staining for epithelial cell identification: Cells are collected using the method described earlier and were stained using Giemsa to allow for histological examination of the cells collected in the swab. After the cells are fixed in 2\% PFA, they are spotted on poly-L-lysine coated coverslips (see above). Next, the cells are stained with Giemsa (1:50 in $0.2 \mathrm{M}$ acetate buffer, $\mathrm{pH}=3.36$ ) (VWR International, Radnor, PA) for $1 \mathrm{~h}$ at RT. After incubation, the cells are washed twice with milliQ water. Next, the slides are mounted with DPX (VWR International, Radnor, PA). Finally, images are acquired with a Nikon Eclipse Ti microscope using a $20 \times$ dry objective for brightfield image acquisition (Nikon, Tokyo, Japan).

Statistics: Statistical analyses is performed using GraphPad Prism 7.02 (GraphPad Inc., CA). Induction of DNA DSBs in BM cells is analyzed using repeated measures ANOVA. Both 8-oxo-dG concentrations and FRAP values before and after CBCT are compared using a paired t-test. To perform the above listed parametric tests, values should be normally distributed and the variances should be equal. Should these conditions not be met, non-parametric alternatives are used. $P$ values lower than 0.05 are considered as statistically significant. Age-related effects are not considered during the validation experiment.
Table 1 Overview of scan parameters per patient included in this validation study

\begin{tabular}{|c|c|c|c|c|c|c|c|}
\hline Patient & Age & Sex & Device & $\begin{array}{l}\text { Field of } \\
\text { view }\end{array}$ & $m A s$ & $\boldsymbol{k} V$ & $\begin{array}{l}\text { Acquisition } \\
\text { time } \\
\text { (seconds) }\end{array}$ \\
\hline 1 & 57 & Female & $\begin{array}{l}\text { Newtom } \\
\text { VGi evo }\end{array}$ & $10 \times 5$ & 11 & 110 & 5 \\
\hline 2 & 41 & Female & $\begin{array}{l}\text { Newtom } \\
\text { VGi evo }\end{array}$ & $10 \times 5$ & 6 & 110 & 5 \\
\hline 3 & 30 & Female & $\begin{array}{l}\text { Newtom } \\
\text { VGi evo }\end{array}$ & $10 \times 10$ & 8 & 110 & 5 \\
\hline 4 & 30 & Male & $\begin{array}{l}\text { Newtom } \\
\text { VGi evo }\end{array}$ & $10 \times 10$ & 10 & 110 & 5 \\
\hline 5 & 71 & Male & $\begin{array}{l}\text { Newtom } \\
\text { VGi evo }\end{array}$ & $10 \times 10$ & 8 & 110 & 5 \\
\hline 6 & 27 & Female & $\begin{array}{l}\text { Newtom } \\
\text { VGi evo }\end{array}$ & $10 \times 10$ & 8 & 110 & 5 \\
\hline
\end{tabular}

$\mathrm{kV}$, kilovoltage; mAs, milliamperage.

\section{Results}

Validation of the described protocol was performed on samples collected from adults (Table 1). BM cells were collected from adult volunteers $(n=6)$ using buccal swabs. Characterization of the cells collected by the swabs was performed using flow cytometrical and light microscopical analysis. $\mathrm{CK} 4^{+}$cells (that were in $\mathrm{G}_{1} /$ $\mathrm{G}_{0}$ phase) were identified as BM cells. Flow cytometrical analysis showed that $97.1 \pm 1.4 \%$ of the cells were $\mathrm{CK}^{+} \mathrm{BM}$ cells, whereas less than $1 \%$ of cells were $\mathrm{CD} 45^{+}$. These $\mathrm{CD} 45^{+}$cells are most likely leukocytes (Figure 3). Further histological analysis confirmed that the collected cells are indeed BM cells, in various stages of exfoliation: some are nucleated, while others are not (Figure 4A, arrowheads).

The presence of DNA DSBs in BM cells was detected using an immunocytochemical staining for $\gamma \mathrm{H} 2 \mathrm{AX}$ and 53BP1 (Figure 4B-E). Analysis of colocalized $\gamma \mathrm{H} 2 \mathrm{AX}$ and 53BP1 foci shows that $0.015 \pm 0.012$ foci/nuclei were counted before $\mathrm{CBCT}$ and $0.028 \pm 0.028$ foci/nuclei were counted after $(p=0.99)$.

Saliva samples were collected from adults that were subjected to CBCT examination twice: once without IR exposure (sham control $=$ Group 1 ) and once with IR exposure (=Group 2$)$. These samples $(n=5)$ were used to validate the protocols for the 8-oxo-dG and FRAP determination.

The change in 8-oxo-dG levels before and after CBCT exposure between Group 1 and Group two was compared. Group one showed no difference $(-0.09 \pm$ $0.44 \mathrm{ng} \mathrm{ml}^{-1} ; p=0.88$ ) in 8-oxo-dG levels whereas an increasing trend was found in Group $2(2.5 \pm 3.0 \mathrm{ng}$ $\mathrm{ml}^{-1} ; p=0.19$ ). Comparison of the changes in both groups was not significant ( $p=0.15$ ), but it shows that after IR exposure (due to CBCT examination) changes in 8-oxo-dG levels can be detected.

In combination with the 8-oxo-dG ELISA, a FRAP assay was performed. When comparing FRAP values 

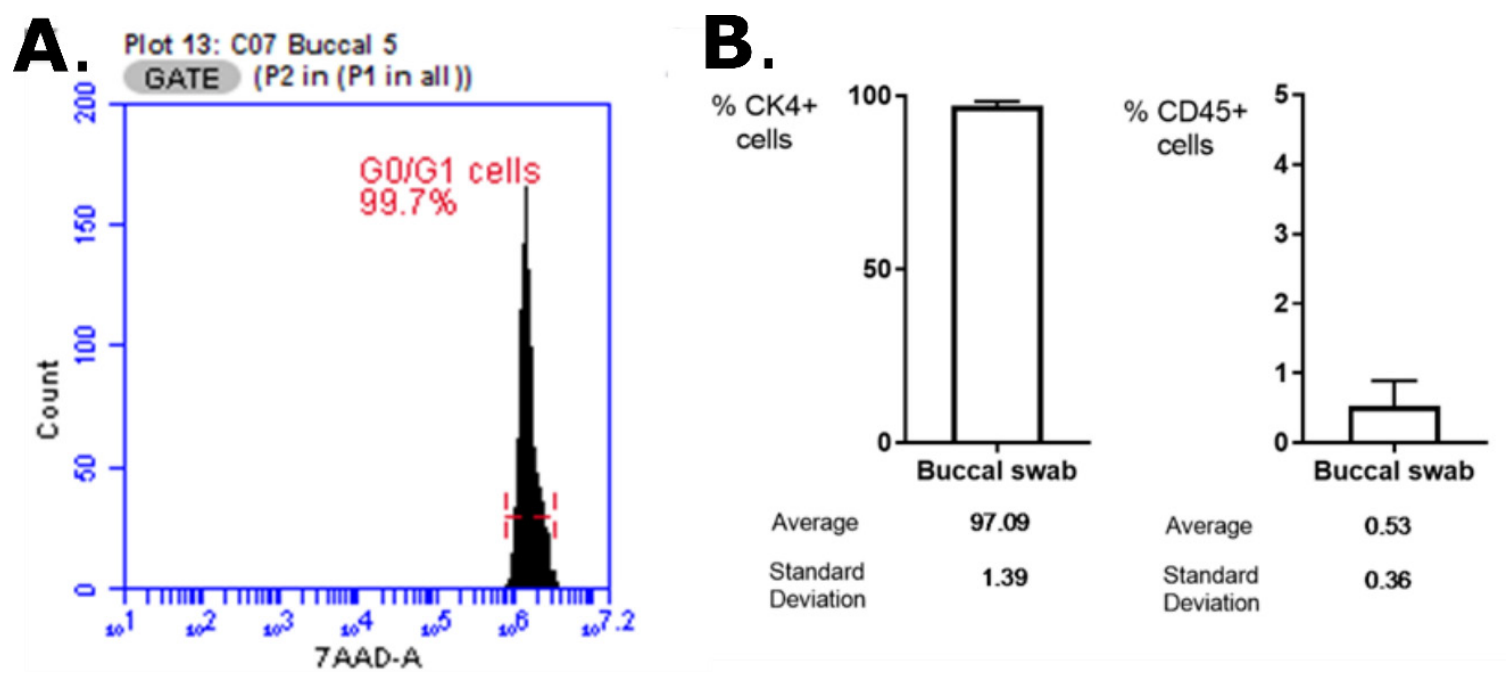

Figure 3 Flow cytometrical identification of cells collected by buccal swab. (A) Overview of the cells that were in $\mathrm{G}_{1} / \mathrm{G}_{0}$ phase. Note that no $\mathrm{S}$ or $\mathrm{G}_{2} / \mathrm{M}$ phase were observed, indicating that the cells are fully differentiated cells. (B) Over $97 \%$ of the cells collected by buccal swab are $\mathrm{CK}^{+}$ epithelial cells (=buccal cells), whereas less than $1 \%$ are $\mathrm{CD}_{4} 5^{+}$, indicating that cells of hematological lineage are present $(N=6)$.

before and after $\mathrm{CBCT}$ examination, results show that the FRAP value does not change in Group $1(-3.6 \pm 69$; $p>0.99)$, but there is a decreasing trend in Group 2 (-18 $\pm 49 ; p=0.31)$. The change between both groups does not differ significantly $(p=0.89)$, but these data show that after IR exposure (due to CBCT examination) changes in FRAP values can be detected.

\section{Discussion}

Currently, the main challenge in the field of radiation protection is identifying biomarkers that allow detection of cellular and subcellular changes due to exposure to low doses of IR $(<0.1 \mathrm{~Gy})$. These biomarkers could then be used to predict low dose IR-associated risks. To this end, blood is the most commonly used sample to study cellular and subcellular changes in the low dose range,
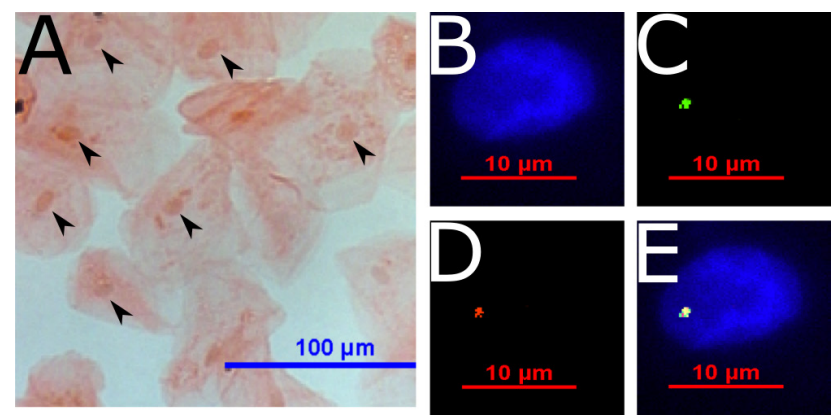

Figure 4 Microscopical identification of cells collected by buccal swab. (A) Giemsa stain clearly shows nucleated epithelial cells (arrowheads), as well as unnucleated cells. This indicates that cells from all mucosal layers are collected. Enough nucleated cells are collected to perform immunocytochemistry. (B-E) Buccal cells with DNA double strand break identified by colocolization of $\gamma \mathrm{H} 2 \mathrm{AX}$ and 53BP1. (B) Buccal cell nucleus, DAPI stain. (C) $\gamma \mathrm{H} 2 \mathrm{AX}$-positive focus. (D) 53BP1-positive focus. (E) Merged image of B, D and E. such as the doses used in medical diagnostic imaging. Blood contains numerous cells that can be used for a variety of assays used in low dose radiation research, such as the micronucleus assay, dicentric assay, comet assay, $\gamma \mathrm{H} 2 \mathrm{AX}$ assay, oxidative stress tests (e.g., 8-oxo$\mathrm{dG}$ ) and even gene expression assays. ${ }^{70-76}$ The advantage of blood sampling is that a standardized protocol can be used, the procedure is easy and small volumes suffice for most tests performed. However, the major limitation of drawing blood is that the procedure is invasive, which can cause discomfort to the patient, especially to pediatric patients. ${ }^{70}$

The DIMITRA Research Group provides a two-part protocol to assess potential cellular and subcellular effects after exposure to low doses of IR, i.e. CBCT examinations. This protocol focusses on non-invasive samples, i.e. BM cells and saliva samples. Compared to blood samples, BM cells and saliva samples have several major advantages: collection is non-invasive, cheap, painless and therefore allows easy repeated sampling. ${ }^{50,51,53}$ This opens new opportunities for use in (oral) healthcare with an increased suitability when pediatric patients are involved. The two-part protocol focusses on detection of DNA DSBs and oxidative stress markers. Oxidative stress can induce oxidative DNA damage which has mutagenic and tumorigenic potential. ${ }^{77}$ DNA DSBs, which can (partly) be caused by oxidative stress, is associated with carcinogenesis, an important health risk related to IR exposure. ${ }^{78,79}$ Therefore, DNA DSB formation and repair are important markers to assess potential health risks in patients exposed to IR.

The current paper describes and validates this two-part protocol. The collection method for BM cells was validated by flow cytometry (presence of $\mathrm{G}_{1}$ I $\mathrm{G}_{0}$ Phase $\mathrm{CK}^{+}$cells) and light microscopy (Giemsa staining). BM cells from different mucosal layers were 
collected, although the majority of the cells were nucleated. These results show that this collection method yields sufficient BM cells for microscopical analysis. The use of $\gamma \mathrm{H} 2 \mathrm{AX}$ foci in BM cells is described before as is the use of a $\gamma \mathrm{H} 2 \mathrm{AX} / 53 \mathrm{BP} 1$ immunofluorescent staining for the detection of DNA DSBs. ${ }^{51,64,80-82}$ However, to the best of our knowledge, this is the first time that a protocol is proposed to detect DNA DSBs after CBCT examination, although other genotoxicity markers have been published before. ${ }^{83}$ Our validation data show that that ex vivo BM cells can be used to perform $\gamma \mathrm{H} 2 \mathrm{AX} / 53 \mathrm{BP} 1$ analysis. Future studies will investigate whether age-dependent differences can be detected in the amount of DNA DSBs after CBCT examination. For saliva collection, a protocol was described based on the passive drool method, after which the samples are immediately stored at $-20^{\circ} \mathrm{C}$. Comparison between sham exposure and IR exposure, i.e. CBCT examination, shows that changes in 8-oxo-dG and FRAP levels can be detected in saliva samples after CBCT examination. These findings confirm that the methods described in this paper are suited for evaluating potential effects of low dose IR exposure in BM cells and saliva samples. The changes detected here are small, but can be attributed to the age of the volunteers: adults are more radioresistant than children, therefore we hypothesize that the effects of low dose IR exposure might be greater in children.

Despite the aforementioned advantages and validation of the DIMITRA study protocol, some precautions should be taken into account when using BM cells and saliva. BM consists of several layers of cells, thus sampling should be done in an uniformed way to avoid differences in cell type distribution. For example, it is known that the amount of basal cells increases when the cheek is sampled repeatedly. ${ }^{48,50}$ Therefore, the authors suggest to collect some test samples prior to the actual study and to characterize the cells that are collected, as described earlier. Although cigarette/cigar smoke is a known cytotoxin and genotoxin to $\mathrm{BM}$ cells, ${ }^{84}$ one limitation of this validation protocol is that 'smoking' was not included in the exclusion criteria. Therefore, it is recommended to add 'smoking' as an exclusion criterion when conducting studies in which BM cells are collected for this type of study.

Saliva composition can be affected by several factors, such as the collection itself, time of day, intake of antioxidants, time since tooth-brushing, presence of blood, drug intake, etc.. Moreover, some (pediatric) patients might not be able to produce (enough) saliva spontaneously. However, the authors recommend to not induce salivation actively, since this will create a bias when compared with spontaneous salivation. ${ }^{35}$ To keep this type of bias to a minimum, our protocol is based on the passive drooling method to collect saliva, which is regarded as the gold standard. ${ }^{67}$ Additional information from the patients on drug intake, previous radiation exposure, etc. should be obtained as well through a questionnaire.
For the post-imaging assessment, $30 \mathrm{~min}$ and 24 $\mathrm{h}$ were chosen for $\gamma \mathrm{H} 2 \mathrm{AX} / 53 \mathrm{BP} 1$ staining based on previous results from $\mathrm{SCK} \cdot \mathrm{CEN}$, in which the peak response is seen after 30 to $60 \mathrm{~min}$ and most DNA damage is resolved after $24 \mathrm{~h}^{62-64}$ For the 8 -oxo-dG analysis and FRAP assay, we chose time points based on Haghdoost et al, who tested 8-oxo-dG after 30 min. ${ }^{69}$ This coincides with BM cell sampling, which is an advantage since this way DNA DSB and 8-oxo-dG levels can be correlated. The results show that changes, especially in oxidative stress markers, can be detected at this time. However, it is possible that the selected time points are not the most optimal ones. Finally, we are not certain that the described methods for detecting DNA damage will be sensitive enough to detect changes following CBCT examination in children, since to the best of the authors' knowledge, this type of study has not been performed before. Current time points are selected based on literature, as mentioned above, but also out of practical consideration: i.e. not letting the patient wait too long after the CBCT examination. If necessary, and if patients are willing, it may be possible to include additional time points (e.g. $60 \mathrm{~min}$ after CBCT examination).

The DIMITRA study protocol presented here is designed to be cost effective, quick, painless and non-invasive. The use of this protocol, however, is not limited to this study and can be easily implemented in other (radio)biological studies. For example, this protocol can be used in a similar setting in which patients are exposed to a head and neck CT, or in cancer patients treated for head and neck cancer. Furthermore, the use of saliva can be used to monitor patients exposed to short- and long-lived radionuclides for diagnostics/therapy. These examples expand the use of this protocol from risk assessment in medical diagnostics, to follow-up/monitoring of radiotherapy patients, two distinctive field in medicine using ionizing radiation.

\section{Conclusion}

It is well-known that children are more radiosensitive than adults. Together with the increasing amount of radiological examinations annually, this has recently led to societal concerns about exposure to IR during medical procedures. The DIMITRA Research Group presents a dedicated, two-part protocol to analyze potential age-related biological differences in response to CBCT examinations in both pediatric and adult patients. This protocol was validated for collecting BM cells and saliva, as well as for analyzing BM cells and saliva samples for DNA damage and oxidative stress markers, respectively. After validation in this paper, this dedicated protocol can be used in different age categories to detect potential cellular and subcellular effects following dental CBCT imaging. 


\section{Acknowledgements}

The DIMITRA Research Group (www.dimitra.be) that contributed to this paper consists of N. Belmans, M. Moreels, S. Baatout, B. Salmon, A.C. Oenning, C. Chaussain, C. Lefevre, M. Hedesiu, P. Virag, M. Baciut, M. Marcu, O. Almasan, R. Roman, I. Barbur, C. Dinu, H. Rotaru, L. Hurubeanu, V. Istouan, O. Lucaciu, D. Leucuta, B. Crisan, L. Bogdan, C. Candea, S. Bran, G. Baciut, R. Jacobs, H. Bosmans, R. Bogaerts, C. Politis, A. Stratis, R. Pauwels, K. de F. Vasconcelos, L. Nicolielo, G. Zhang, E. Tijskens, M. Vranckx, A. Ockerman, E. Claerhout, E. Embrechts.

\section{References}

1. Arai Y, Tammisalo E, Iwai K, Hashimoto K, Shinoda K. Development of a compact computed tomographic apparatus for dental use. Dentomaxillofac Radiol 1999; 28: 245-8. doi: https:// doi.org/10.1038/sj.dmfr.4600448

2. Mozzo P, Procacci C, Tacconi A, Martini PT, Andreis IA. A new volumetric CT machine for dental imaging based on the conebeam technique: preliminary results. Eur Radiol 1998; 8: 1558-64. doi: https://doi.org/10.1007/s003300050586

3. Scarfe WC, Farman AG. What is cone-beam CT and how does it work? Dent Clin North Am 2008; 52: 707-30v.. doi: https://doi.org/ 10.1016/j.cden.2008.05.005

4. Pauwels R. Cone beam CT for dental and maxillofacial imaging: dose matters. Radiat Prot Dosimetry 2015; 165(1-4): 156-61. doi: https://doi.org/10.1093/rpd/ncv057

5. Dawood A, Patel S, Brown J. Cone beam CT in dental practice. $\mathrm{Br}$ Dent $J$ 2009; 207: 23-8. doi: https://doi.org/10.1038/sj.bdj.2009. 560

6. Kapila SD, Nervina JM. CBCT in orthodontics: assessment of treatment outcomes and indications for its use. Dentomaxillofac Radiol 2015; 44: 20140282. doi: https://doi.org/10.1259/dmfr. 20140282

7. Scarfe WC, Farman AG, Levin MD, Gane D, Scarfe WC, Farman AG, et al. Essentials of maxillofacial cone beam computed tomography - Clinical applications of cone-beam computed tomography in dental practice. Alpha Omegan 2010; 103: 62-7.

8. De Vos W, Casselman J, Swennen GRJ. Cone-beam computerized tomography (CBCT) imaging of the oral and maxillofacial region: a systematic review of the literature. Int J Oral Maxillofac Surg 2009; 38: 609-25. doi: https://doi.org/10.1016/j.ijom.2009.02. 028

9. Feldkamp LA, Davis LC, Kress JW, Algorithm PC-B. Practical cone-beam algorithm. J Opt Soc Am A 1984; 1: 612-9. doi: https:// doi.org/10.1364/JOSAA.1.000612

10. Suomalainen A, Pakbaznejad Esmaeili E, Robinson S. Dentomaxillofacial imaging with panoramic views and cone beam CT. Insights Imaging 2015; 6: 1-16. doi: https://doi.org/10.1007/ s13244-014-0379-4

11. Shah N, Bansal N, Logani A. Recent advances in imaging technologies in dentistry. World J Radiol 2014; 6: 794-807. doi: https:// doi.org/10.4329/wjr.v6.i10.794

12. Scarfe WC, Farman AG, Sukovic P. Clinical applications of conebeam computed tomography in dental practice. J Can Dent Assoc 2006; 72: 75-80.

13. UNSCEAR Sources and effects of ionizing radiation. 2000; Volume II: Effects.

14. UNSCoUReport: sources. effects and risks of ionizing radiation. 2013; II Annex B - Effects of radiation exposure of children 2013;

15. Ludlow JB, Davies-Ludlow LE, White SC. Patient risk related to common dental radiographic examinations: the impact of 2007 International Commission on radiological protection recommen-

\section{Funding}

The research leading to these results has received funding from the European Atomic Energy Community's Seventh Framework Programme FP7/2007-2011 under grant agreement $n^{\circ} 604984$ (OPERRA: Open Project for the European Radiation Research Area). The OPERRA consortium had no role in study design, data collection and analysis, decision to publish, or preparation of the manuscript. NB is supported by a UHasselt-SCK • CEN PhD grant.

dations regarding dose calculation. $J$ Am Dent Assoc 2008; 139: 1237-43(1939)

16. Pauwels R, Beinsberger J, Collaert B, Theodorakou C, Rogers J, Walker A, et al. Effective dose range for dental cone beam computed tomography scanners. Eur J Radiol 2012; 81: 267-71. doi: https://doi.org/10.1016/j.ejrad.2010.11.028

17. Oenning AC, Jacobs R, Pauwels R, Stratis A, Hedesiu M, Salmon B, et al. Cone-beam CT in paediatric dentistry: DIMITRA project position statement. Pediatr Radiol 2018; 48: 308-316. doi: https://doi.org/10.1007/s00247-017-4012-9

18. Marcu M, Hedesiu M, Salmon B, Pauwels R, Stratis A, Oenning ACC, et al. Estimation of the radiation dose for pediatric CBCT indications: a prospective study on ProMax3D. Int J Paediatr Dent 2018; 28: 300-9. doi: https://doi.org/10.1111/ipd. 12355

19. Signorelli L, Patcas R, Peltomäki T, Schätzle M. Radiation dose of cone-beam computed tomography compared to conventional radiographs in orthodontics. J Orofac Orthop 2016; 77: 9-15. doi: https://doi.org/10.1007/s00056-015-0002-4

20. Li G. Patient radiation dose and protection from cone-beam computed tomography. Imaging Sci Dent 2013; 43: 63-9. doi: https://doi.org/10.5624/isd.2013.43.2.63

21. Loubele M, Bogaerts R, Van Dijck E, Pauwels R, Vanheusden S, Suetens $\mathrm{P}$, et al. Comparison between effective radiation dose of CBCT and MSCT scanners for dentomaxillofacial applications. Eur J Radiol 2009; 71: 461-8. doi: https://doi.org/10.1016/j.ejrad. 2008.06.002

22. Centre for Radiation CaEH. Guidance on the safe use of dental cone bean CT (computed tomography) equipment. Oxfordshire: Health Protection Agency; 2010.

23. Theodorakou C, Walker A, Horner K, Pauwels R, Bogaerts R, Jacobs R, et al. Estimation of paediatric organ and effective doses from dental cone beam CT using anthropomorphic phantoms. Br J Radiol 2012; 85: 153-60. doi: https://doi.org/10.1259/bjr/ 19389412

24. Department of Public Health EaSDoHP-F, Women and Children's Health Cluster (FWC). Communicating radiation risks in paediatric imaging - Information to support healthcare discussions about benefit and risk. In: . Switserland: World Health Organization; 2016.

25. Brenner DJ, Hall EJ. Computed tomography - an increasing source of radiation exposure. $N$ Engl J Med Overseas Ed 2007; 357: 2277-84. doi: https://doi.org/10.1056/NEJMra072149

26. RadiologyInfo.org Radiation dose in x-ray and CT exams.

27. Bogdanich W. CMJ. Radiation Worries for Children in Dentists' Chairs. New York Times 2010;

28. Brenner DJ. Estimating cancer risks from pediatric CT: going from the qualitative to the quantitative. Pediatr Radiol 2002; 32: 228-31discussion 42-4. doi: https://doi.org/10.1007/s00247-0020671-1 
29. Hall EJ. Lessons we have learned from our children: Cancer risks from diagnostic radiology. Pediatr Radiol 2002; 32: 700-6. doi: https://doi.org/10.1007/s00247-002-0774-8

30. Berrington de González A, Darby S. Risk of cancer from diagnostic X-rays: estimates for the UK and 14 other countries. Lancet 2004; 363: 345-51. doi: https://doi.org/10.1016/S0140-6736(04) 15433-0

31. UNSCEAR. SOURCES AND EFFECTS OF IONIZING RADIATION: UNSCEAR 2008 Report. New York: United Nations; 2010.

32. Holmberg O, Czarwinski R, Mettler F. The importance and unique aspects of Radiation protection in medicine. Eur J Radiol 2010; 76: 6-10. doi: https://doi.org/10.1016/j.ejrad.2010.06.031

33. Maurya TPAD DK. Role of Radioprotectors in the Inhibition of DNA Damage and Modulation of DNA Repair After Exposure to Gamma-Radiation. In: editor.Chen CC. Selected Topics in DNA Repair: InTech; 2011.

34. Chapple ILC, Matthews JB. The role of reactive oxygen and antioxidant species in periodontal tissue destruction. Periodontol 2000 2007; 43: 160-2322000. doi: https://doi.org/10.1111/j.1600-0757. 2006.00178.x

35. Tóthová L'ubomíra, Kamodyová N, Červenka T, Celec P. Salivary markers of oxidative stress in oral diseases. Front Cell Infect Microbiol 2015; 5: 73. doi: https://doi.org/10.3389/fcimb.2015. 00073

36. Cooke MS, Evans MD, Dizdaroglu M, Lunec J. Oxidative DNA damage: mechanisms, mutation, and disease. Faseb $J$ 2003; 17: 1195-214. doi: https://doi.org/10.1096/fj.02-0752rev

37. Kasai H, Nishimura S. Hydroxylation of deoxy guanosine at the C-8 position by polyphenols and aminophenols in the presence of hydrogen peroxide and ferric ion. Gan 1984; 75: 565-6.

38. Löbrich M, Shibata A, Beucher A, Fisher A, Ensminger M, Goodarzi AA, et al. gammaH2AX foci analysis for monitoring DNA double-strand break repair: strengths, limitations and optimization. Cell Cycle 2010; 9: 662-9. doi: https://doi.org/10.4161/ cc.9.4.10764

39. Dugle DL, Gillespie CJ, Chapman JD. DNA strand breaks, repair, and survival in x-irradiated mammalian cells. Proc Natl Acad Sci US A 1976; 73: 809-12. doi: https://doi.org/10.1073/pnas.73.3.809

40. Olive PL. The role of DNA single- and double-strand breaks in cell killing by ionizing radiation. Radiat Res 1998; 150(5 Suppl): S42-51. doi: https://doi.org/10.2307/3579807

41. Jackson SP. Sensing and repairing DNA double-strand breaks. Carcinogenesis 2002; 23: 687-96. doi: https://doi.org/10.1093/ carcin/23.5.687

42. Richardson C, Jasin M. Frequent chromosomal translocations induced by DNA double-strand breaks. Nature 2000; 405: 697700. doi: https://doi.org/10.1038/35015097

43. Vamvakas S, Vock EH, Lutz WK. On the role of DNA doublestrand breaks in toxicity and carcinogenesis. Crit Rev Toxicol 1997; 27: 155-74. doi: https://doi.org/10.3109/10408449709021617

44. Khanna KK, Jackson SP. DNA double-strand breaks: signaling, repair and the cancer connection. Nat Genet 2001; 27: 247-54. doi: https://doi.org/10.1038/85798

45. Kinner A, Wu W, Staudt C, Iliakis G. Gamma-H2AX in recognition and signaling of DNA double-strand breaks in the context of chromatin. Nucleic Acids Res 2008; 36: 5678-94. doi: https://doi. org/10.1093/nar/gkn550

46. Riches LC, Lynch AM, Gooderham NJ. Early events in the mammalian response to DNA double-strand breaks. Mutagenesis 2008; 23: 331-9. doi: https://doi.org/10.1093/mutage/gen039

47. Ciccia A, Elledge SJ. The DNA damage response: making it safe to play with knives. Mol Cell 2010; 40: 179-204. doi: https://doi. org/10.1016/j.molcel.2010.09.019

48. Torres-Bugarín O, Zavala-Cerna MG, Nava A, Flores-García A, Ramos-Ibarra ML. Potential uses, limitations, and basic procedures of micronuclei and nuclear abnormalities in buccal cells. Dis Markers 2014; 2014: 1-13. doi: https://doi.org/10.1155/2014/ 956835

49. Spivack SD, Hurteau GJ, Jain R, Kumar SV, Aldous KM, Gierthy JF, et al. Gene-environment interaction signatures by quantitative mRNA profiling in exfoliated buccal mucosal cells. Cancer Res 2004; 64: 6805-13. doi: https://doi.org/10.1158/00085472.CAN-04-1771

50. Thomas P, Holland N, Bolognesi C, Kirsch-Volders M, Bonassi S, Zeiger E, et al. Buccal micronucleus cytome assay. Nat Protoc 2009; 4: 825-37. doi: https://doi.org/10.1038/nprot.2009.53

51. Siddiqui MS, François M, Fenech MF, Leifert WR. $\gamma \mathrm{H} 2 \mathrm{AX}$ responses in human buccal cells exposed to ionizing radiation. Cytometry A 2015; 87: 296-308. doi: https://doi.org/10.1002/cyto. a. 22607

52. Sarto F, Tomanin R, Giacomelli L, Iannini G, Cupiraggi AR. The micronucleus assay in human exfoliated cells of the nose and mouth: application to occupational exposures to chromic acid and ethylene oxide. Mutat Res 1990; 244: 345-51. doi: https://doi. org/10.1016/0165-7992(90)90083-V

53. Lee JM, Garon E, Wong DT, diagnostics S. Salivary diagnostics. Orthod Craniofac Res 2009; 12: 206-11. doi: https://doi.org/10. 1111/j.1601-6343.2009.01454.x

54. Mandel ID. Salivary diagnosis: more than a lick and a promise. J Am Dent Assoc 1993; 124: 85-7(1939). doi: https://doi.org/10. 14219/jada.archive.1993.0007

55. Miller SM. Saliva testing--a nontraditional diagnostic tool. Clin Lab Sci 1994; 7: 39-44.

56. Dame ZT, Aziat F, Mandal R, Krishnamurthy R, Bouatra S, Borzouie S, et al. The human saliva metabolome. Metabolomics 2015; 11: 1864-83. doi: https://doi.org/10.1007/s11306-015-0840-5

57. ICRP. Recommendations of the ICRP. ICRP Publication 26; 1977(Ann. ICRP 1 (3)).

58. ICRP Recommendations of the International Commission on radiological protection. ICRP publication 60. 1991. Ann. ICRP 1990;21 (1-3).

59. Recommendations of the International Commission on radiological protection. ICRP publication 103. 2007. Ann. ICRP 2007;37 (2-4).

60. Stratis A. Customized Monte Carlo Modelling for Paediatric Patient Dosimetry in Dental and Maxillofacial Cone Beam Computed Tomography Imaging [Doctoral Thesis]. KU Leuven: Leuven University Press; 2018.

61. Virag P, Hedesiu M, Soritau O, Perde-Schrepler M, Brie I, Pall E, et al. Low-dose radiations derived from cone-beam CT induce transient DNA damage and persistent inflammatory reactions in stem cells from deciduous teeth. Dentomaxillofac Radiol 2018; 47: 20170462. doi: https://doi.org/10.1259/dmfr.20170462

62. Suetens A, Konings K, Moreels M, Quintens R, Verslegers M, Soors E, et al. Higher initial dna damage and persistent cell cycle arrest after carbon ion irradiation compared to x-irradiation in prostate and colon cancer cells. Front Oncol 2016; 6(Suppl): 87. doi: https://doi.org/10.3389/fonc.2016.00087

63. Ghardi M, Moreels M, Chatelain B, Chatelain C, Baatout S. Radiation-induced double strand breaks and subsequent apoptotic DNA fragmentation in human peripheral blood mononuclear cells. Int J Mol Med 2012; 29: 769-80. doi: https://doi.org/ 10.3892/ijmm.2012.907

64. Baselet B, Belmans N, Coninx E, Lowe D, Janssen A, Michaux A, et al. Functional gene analysis reveals cell cycle changes and inflammation in endothelial cells irradiated with a single X-ray dose. Front Pharmacol 2017; 8: 213. doi: https://doi.org/10.3389/fphar. 2017.00213

65. Schindelin J, Arganda-Carreras I, Frise E, Kaynig V, Longair M, Pietzsch T, et al. Fiji: an open-source platform for biological-image analysis. Nat Methods 2012; 9: 676-82. doi: https://doi.org/10. 1038/nmeth.2019

66. De Vos WH, Van Neste L, Dieriks B, Joss GH, Van Oostveldt P. High content image cytometry in the context of subnuclear organization. Cytometry A 2010; 77: 64-75.

67. Munro CL, Grap MJ, Jablonski R, Boyle A. Oral health measurement in nursing research: state of the science. Biol Res Nurs 2006; 8: 35-42. doi: https://doi.org/10.1177/1099800406289343

68. Shakeri Manesh S, Sangsuwan T, Pour Khavari A, Fotouhi A, Emami SN, Haghdoost S. MTH1, an 8-oxo-2'-deoxyguanosine triphosphatase, and MYH, a DNA glycosylase, cooperate to 
inhibit mutations induced by chronic exposure to oxidative stress of ionising radiation. Mutagenesis 2017; 32: 389-96. doi: https:// doi.org/10.1093/mutage/gex003

69. Haghdoost S, Czene S, Näslund I, Skog S, Harms-Ringdahl M. Extracellular 8-oxo-dG as a sensitive parameter for oxidative stress in vivo and in vitro. Free Radic Res 2005; 39: 153-62. doi: https://doi.org/10.1080/10715760500043132

70. Vandevoorde C, Gomolka M, Roessler U, Samaga D, Lindholm C, Fernet M, et al. EPI-CT: in vitro assessment of the applicability of the $\gamma$-H2AX-foci assay as cellular biomarker for exposure in a multicentre study of children in diagnostic radiology. Int $J$ Radiat Biol 2015; 91: 653-63. doi: https://doi.org/10.3109/09553002.2015. 1047987

71. El-Saghire H, Thierens H, Monsieurs P, Michaux A, Vandevoorde C, Baatout S. Gene set enrichment analysis highlights different gene expression profiles in whole blood samples $\mathrm{x}$-irradiated with low and high doses. Int J Radiat Biol 2013; 89: 628-38. doi: https://doi.org/10.3109/09553002.2013.782448

72. Sudprasert W, Navasumrit P, Ruchirawat M. Effects of low-dose gamma radiation on DNA damage, chromosomal aberration and expression of repair genes in human blood cells. Int J Hyg Environ Health 2006; 209: 503-11. doi: https://doi.org/10.1016/j.ijheh. 2006.06.004

73. Ponzinibbio MV, Crudeli C, Peral-García P, Seoane A. Low-dose radiation employed in diagnostic imaging causes genetic effects in cultured cells. Acta Radiol 2010; 51: 1028-33. doi: https://doi.org/ $10.3109 / 02841851.2010 .517561$

74. Das Roy L, Giri S, Singh S, Giri A. Effects of radiation and vitamin C treatment on metronidazole genotoxicity in mice. Mutat Res 2013; 753: 65-71. doi: https://doi.org/10.1016/j.mrgentox.2013.02.001

75. Ainsbury EA, Al-Hafidh J, Bajinskis A, Barnard S, Barquinero JF, Beinke $\mathrm{C}$, et al. Inter- and intra-laboratory comparison of a multibiodosimetric approach to triage in a simulated, large scale radiation emergency. Int J Radiat Biol 2014; 90: 193-202. doi: https:// doi.org/10.3109/09553002.2014.868616
76. Sangsuwan T, Haghdoost S. The nucleotide pool, a target for low-dose gamma-ray-induced oxidative stress. Radiat Res 2008; 170: 776-83. doi: https://doi.org/10.1667/RR1399.1

77. Tsuzuki T, Nakatsu Y, Nakabeppu Y. Significance of erroravoiding mechanisms for oxidative DNA damage in carcinogenesis. Cancer Sci 2007; 98: 465-70. doi: https://doi.org/10.1111/j. 1349-7006.2007.00409.x

78. Magnander K, Elmroth K. Biological consequences of formation and repair of complex DNA damage. Cancer Lett 2012; 327(1-2): 90-6. doi: https://doi.org/10.1016/j.canlet.2012.02.013

79. Kryston TB, Georgiev AB, Pissis P, Georgakilas AG. Role of oxidative stress and DNA damage in human carcinogenesis. Mutat Res 2011; 711(1-2): 193-201. doi: https://doi.org/10.1016/ j.mrfmmm.2010.12.016

80. González JE, Roch-Lefèvre SH, Mandina T, García O, Roy L. Induction of gamma-H2AX foci in human exfoliated buccal cells after in vitro exposure to ionising radiation. Int J Radiat Biol 2010; 86: 752-9. doi: https://doi.org/10.3109/09553002.2010.484476

81. Vandevoorde C, Vral A, Vandekerckhove B, Philippé J, Thierens H. Radiation Sensitivity of Human CD $34^{(+}$) Cells Versus Peripheral Blood T Lymphocytes of Newborns and Adults: DNA Repair and Mutagenic Effects. Radiat Res 2016; 185: 580-90. doi: https:// doi.org/10.1667/RR14109.1

82. Deminice R, Sicchieri T, Payão PO, Jordão AA. Blood and salivary oxidative stress biomarkers following an acute session of resistance exercise in humans. Int J Sports Med 2010; 31: 599-603. doi: https://doi.org/10.1055/s-0030-1255107

83. da Fonte JB, Andrade TMde, Albuquerque RL, de Melo MdeFB, Takeshita WM. Evidence of genotoxicity and cytotoxicity of $\mathrm{X}$-rays in the oral mucosa epithelium of adults subjected to cone beam CT. Dentomaxillofac Radiol 2018; 47: 20170160. doi: https:// doi.org/10.1259/dmfr.20170160

84. de Geus JL, Wambier LM, Bortoluzzi MC, Loguercio AD, Kossatz S, Reis A. Does smoking habit increase the micronuclei frequency in the oral mucosa of adults compared to non-smokers? A systematic review and meta-analysis. Clin Oral Investig 2018; 22: 81-91. doi: https://doi.org/10.1007/s00784-017-2246-4 